\title{
Impact of family income on anthropometric measurement of Primary School children
}

\author{
ANKITA TYAGI AND PRIYANKA SHARMA
}

Received: 09.08.2016; Revised: 09.10.2016; Accepted: 24.10 .2016

See end of the paper for authors' affiliations ANKITA TYAGI

Department of Home Science, Swami

Vivekanand Subharti University, MEERUT

(U.P.) INDIA

Email : tyagiankita20@gmail.com
ABSTRACT : The investigation was carried out to study the impact of family income on the anthropometric measurements of Primary School (PS) children selected from three different schools of high, middle and low educational standards and expenses. The effect of family income on body dimensions like height, weight, MUAC, skinfold thickness, weight for age, height for age and weight for height were studied. The family income of three different groups were estimated by using interview method and by filling proformas. The anthropometric measurements were assessed by using weight balance for weight, vertical anthropometric rod for height, Zerfas tape for MUAC, Harper's caliper for skinfold thickness. These anthropometric measurements were then compared with the NCHS standards. Statistical procedures viz., percentage, mean, correlation co-efficient and standard deviation were used. The results showed that the anthropometric measurements of Primary School (PS) children is significantly affected by family income.

KEY WORDS: Anthropometric measurements, Skinfold thickness, Family income, Malnutrition, Mid upper arm circumference

- HOW TO CITE THIS PAPER : Tyagi, Ankita and Sharma, Priyanka (2016). Impact of family income on anthropometric measurement of Primary School children. Asian J. Home Sci., 11 (2) : 361-366, DOI: 10.15740/HAS/AJHS/11.2/361-366. 